\title{
Managing Groups and Teams
}

\author{
Ecler Ercole Jaqua, MD, DipABLM, DipABOM, FAAFP ${ }^{1^{*}}$ \\ Terry Jaqua, PhDc, MBA-HRM, SHRM-CP, PHR ${ }^{2}$ \\ ${ }^{1}$ Loma Linda University Health - Family Medicine Department, USA \\ ${ }^{2}$ Trident University International - Health Sciences Department, USA
}

*Corresponding Author: Ecler Jaqua, MD, DipABLM, DipABOM, FAAFP - Loma Linda University Health - Family Medicine Department, USA.

\section{INTRODUCTION}

Academicians and management gurus have reinforced the importance of teamwork. According to Drucker (1992), for an organization to be successful, it must be established as a team. On the other hand, Katzenbach and Smith (1993) posit that the main constituent of organizational performance in the future will be teams. In the year 2000, it is estimated that 82 percent of Fortune 2000 businesses had more than half of their personnel working in groups (Flores \& Gray, 2000). The main leadership concept is managing teams and groups. At one point in life, we have belonged to groups such as musical groups or athletic teams. Collaboration occurs when a group of people or two individuals work together to achieve a goal by sharing skills and ideas. With technological advancement, communication and sharing files using cloud-based software package has become more common.

\section{CONCRETE EXPERIENCE}

Before practicing medicine, I worked in a marketing firm where we collaborated and participated in frequent collaboration with groups and teams. I had a vital assignment, so our marketing team participated in a critical campaign for a famous brand. In my portfolio, it was, without doubt, the largest project. I occupied a low-ranking marketing coordinator position on the project, so I was working hard to make a good impression. Not because I usually endeavor to put forth a bold effort, but because high-ranking individuals from the group had faith in my work. Their confidence and their support in my career were all I expected to raise my work considerably further. Unquestionably it has! This venture allowed me to utilize group work as part of learning and teaching activities in this undertaking. Working in groups can make the job easier, resulting in a fulfilling and involving experience for learners. By participating in group work, I expanded my association with the team, put in more determination, and became progressively preoccupied with finishing the team's assignment. Additionally, working in groups can be demanding at times and requires a lot of skills. I gained valuable facts about task-focused teams, how they work, and the difficulties involved with this assignment.

In the beginning, it was challenging for me to comprehend the entire procedure of the joint effort and communication skills involved. However, by embarking on this venture in teams, I have, without a doubt, built up a more grounded feeling of commitment among the participants and increased confidence in the route for accomplishing the assignment. To be precise, this venture has offered me another understanding of teamwork with a chance of learning team skills. These skills stimulated less reliance on teachers and more self-autonomy.

\section{REFLECTIVE OBSERVATION}

Excellent cooperation performs a vital part in accomplishing and executing common objectives better and quicker in a group venture. Every group member plays their specific duties and takes on various responsibilities, making the team work well and accomplish a goal when combined. In multiple phases of group work, arguments and conflicts may happen as individuals have numerous perspectives that need to be blended within the team. The solution to efficient group work is to use individual team members' capabilities to motivate them towards avoiding their weaknesses.

Every team member had her role distinct from the rest. In line with the Team role theory developed and identified by Dr. Meredit, various persons play different tasks in the team 
to different intensities grouped in nine broad kinds (Belbin .M., 2007). Through recognizing features of several types of functions, the most out of every member can be made, and shortcomings avoided.

As a result of teamwork, I distinctly perceive my job attributes, figure out how to build up my vision and bypass shortcomings in the group, and draw teachings and reflections on the best way to manage crises occurring during teamwork. In the group work experience, it dawned on me that collaboration is not an easy task. Nevertheless, Tuchman's group theory on four stages of team development can aid me to manage and be familiar with numerous problems or unexpected scenarios that might occur during various phases of team development. There are four expressions in group progress; performing, forming, norming, and storming (Tuckman \& Jensen, 1977). In the course of my experience from this group work, both negative and positive situations of the four distinct phases of group development occurred and need focus.

\section{AbStract Conceptualization}

The preliminary phase of group development is the forming stage. Here, group members are not used to one another; therefore, reaching an agreement is an uphill task. Individuals are anxious to find their niche and, therefore, barely feel an acceptance as a member. This is because members are unfamiliar with one another and are not aware of their objective and therefore require a mentor's guidance to know the reason for togetherness. In order to conquer the complications caused by the forming stage and plan for the groups' tasks, meetings were organized to build trust within the team members.

During the meetings, my mentor outlined the procedures for task completion, the team mission, and the whole agenda. The responsibilities were shared out and apportioned to each team member. This stage is significant since it makes way for the smooth development of the following group stages. During the meeting, the shortcomings and strengths of each member are identified. This way, each individual is assigned to complete the most appropriate task. Also, if different responsibilities are allocated to the right individual, the productivity of group work will be significantly raised, thereby reducing group conflicts. As a result, every team member will be motivated.

As the forming stage is completed, team members consider themselves part of the team, sense acceptance and feel inspired to work as a team. According to Tuckman (1977), the storming stage comes as a conflict of perspectives and disagreement of a wide range of thought sufficient to make a storm for both teamwork and brains gradually come together. During the storming stage, individual team members can criticize each other due to different perspectives. Utilizing Tuchman's point of view, contradictions and disagreements symbolize this stage as differences come to light. This will happen on many occasions during group discussions since every team member had a different perspective and towards the same matter.

\section{ACTIVE EXPERIMENTATION}

Owing to the four stages of team growth, I discovered that discipline and functional interactions are very significant to enable collaboration to work more effectively. Furthermore, understandings, mutual respects, and trusts are necessary to accomplish a joint objective.

\section{CONCLUSION}

From the collaboration experience, I firmly feel the importance of joint effort and its admiration for goal achievement and mission completion. Similarly, it has taught me to put group objectives as a priority and to join forces with others, especially now that $I$ work as a physician. On the other hand, reducing shortcomings and capitalizing on strengths to accomplish a groups' common purpose is the allure only teamwork can bring.

\section{REFERENCES}

[1] Belbin, M. (2020). The Nine Belbin Team Roles. Belbin.com. Retrieved 1 May 2020, from http://www.belbin.com/rte.asp?id=8.

[2] Drucker, P. (1992). The New Society of Organizations. Harvard Business Review, 95, 95-104.

[3] Flores, F., \& Gray, J. (2000). Entrepreneurship and the wired life: Work in the Wake of Careers. London 
[4] Smith, D., \& Katzenbach, J. (2017). The Wisdom of Teams. Harvard business school press.
[5] Tuckman, B., \& Jensen, M. (1977). Stages of Small-Group Development Revisited. Group \& Organization Studies, 2(4), 419-427.

Citation: Ecler Ercole Jaqua, MD, DipABLM, DipABOM, FAAFP \& Terry Jaqua, PhDc, MBA-HRM, SHRM-CP, PHR, "Managing Groups and Teams", International Journal of Research Studies in Medical and Health Sciences. 2021; 6(4): 6-8. DOI:https://doi.org/10.22259/ijrsmhs.0604002

Copyright: @ 2021 Ecler Ercole Jaqua, MD, DipABLM, DipABOM, FAAFP \& Terry Jaqua, PhDc, MBAHRM, SHRM-CP, PHR, This is an open-access article distributed under the terms of the Creative Commons Attribution License, which permits unrestricted use, distribution, and reproduction in any medium, provided the original author and source are credited. 